\title{
Profile of stroke patients treated at a rehabilitation centre in Bangladesh
}

\author{
Firoz Ahmed Mamin 1* ${ }^{*}$ Muhammad Shahidul Islam², Farjana Sharmin Rumana ${ }^{2}$ and Farhana Faruqui ${ }^{2}$
}

\begin{abstract}
Objective: Stroke is the leading cause of death and disability in Bangladesh. Rehabilitation services have not yet been integrated into the Bangladesh health system. Only a few non-governmental organisations provide rehabilitation for stroke patients. The demographic profile of these patients has not yet been established. The aim of this study was to identify and evaluate the socio-demographic data, risk factors, place of primary management and cost of stroke for those who attended rehabilitation at the Centre for the Rehabilitation of the Paralysed (CRP), Bangladesh. A cross-sectional survey was carried out among 103 conveniently selected stroke patients who attended CRP between December 2015 and May 2016.

Results: The mean age of the participants was 49 years. The majority (68\%) originated from urban areas. About $85 \%$ of the patients had a history of hypertension prior to their stroke. Following the stroke, most patients received their initial treatment in a general clinic or hospital by registered physicians. Only 22\% of the patients were advised to pursue follow-up rehabilitation services by their physicians. All patients interviewed in the survey received unpaid full-time care from their family members. The reported cost of rehabilitation was approximately US $\$ 328$ per month per patient.
\end{abstract}

Keywords: Stroke, Rehabilitation, Bangladesh, Caregivers

\section{Introduction}

The global burden of disease has shifted in the last few decades from infectious and nutritional disorders to noncommunicable disease [1]. The incidence of stroke has been increasing throughout the world and is particularly prevalent in developing countries where it is now the second leading cause of death [2]. The numbers relating to stroke related deaths and disability are extremely high in developing countries. Globally, developing countries account for approximately $75 \%$ of stroke related deaths and $81 \%$ of stroke related disability-adjusted life-years (DALYs) [3]. Bangladesh is a densely populated developing country and faces the double burden of both communicable and non-communicable diseases [4]. Rapid urbanisation, changing dietary habits, a lack of physical

\footnotetext{
*Correspondence: mamincns@gmail.com

1 Department of Physiotherapy, Bangladesh Health Professions Institute (BHPI), CRP. Savar, Dhaka 1343, Bangladesh

Full list of author information is available at the end of the article
}

activity, consumption of tobacco and a decline in communicable diseases have all contributed to a rising prevalence of chronic diseases such as stroke [5]. Stroke creates a significant burden in an economic and social perspective, and this burden is increasing [6]. Patients often require individualised long-term care and rehabilitation services [7]. Although facilities for acute stroke care have been developing in Bangladesh, rehabilitation services are lagging far behind primary care services [9]. CRP is one of the few centres available for stroke rehabilitation. It should be noted that the demographical information regarding CRP patients is limited [8].

\section{Main text \\ Methods}

\section{Aim of this study}

The aim of this study was to provide an overall view of stroke patients who took-up rehabilitation services at CRP. 
The specific objectives were to;

1. Observe the sociodemographic characteristics of attendees.

2. Identify the risk factors to stroke of this group and assess the association between various socio-demographic characteristics.

3. Identify the prior knowledge on stroke, initial management of stroke, information regarding care-givers and the extent of financial cost for stroke patients attending CRP.

A cross-sectional study of stroke patients who attended CRP for rehabilitation services was conducted between December 2015 and May 2016. We selected participants who had a confirmed diagnosis of stroke by a registered physician, who had been utilising rehabilitation services for at least 1 month at CRP and who had agreed to participate in this study. There was no age limit, and both male and female participants were enlisted. Patients who had a history of stroke, transient ischemic attack (TIA) or surgery for stroke prior to their current admission were excluded. A questionnaire was developed and a pilot study was carried out to finalise the questionnaire, with five physiotherapists trained as data collectors. Data was collected from the participants and, where necessary, from their carers through face-to-face interviews. In terms of occupation, those who were employed, selfemployed or farmers were categorised as employed, and those who were unemployed, housewives or retired were categorised as unemployed.

We used the descriptive statistics to present the data and Pearson's Chi square test to identify the differences among various socio-demographic features and risk factors. A Multivariate logistic regression was performed to determine the association between various sociodemographic data and risk factors. Differences and associations were considered significant when $\mathrm{p}<0.05$. Data analysis was performed using the Statistical Package for the Social Science (SPSS), Version 19.0. Armonk, NY: IBM Corp.

\section{Results}

In the period December 2015 to May 2016, a total of 103 participants were selected for this study based on the selection criteria. Of these individuals, $77.7 \%$ were males and the average age was $49(\mathrm{SD} \pm 8)$ years. Detailed socio-demographic information is given in Table 1.

\section{Risk factors for stroke}

Based on self-reported information, $85 \%$ of the study group had high blood pressure, $69 \%$ had high blood cholesterol and $77 \%$ had diabetes prior to their stroke. About
Table 1 Socio-demographic features of stroke patients

\begin{tabular}{|c|c|c|c|}
\hline Variables & Categories & $\begin{array}{l}\text { Frequency } \\
(N=103)\end{array}$ & Percentage (\%) \\
\hline \multirow[t]{2}{*}{ Gender } & Male & 80 & 77.7 \\
\hline & Female & 23 & 22.3 \\
\hline \multirow[t]{5}{*}{ Age (years) } & $30-40$ & 8 & 7.8 \\
\hline & $41-50$ & 64 & 62.1 \\
\hline & $51-60$ & 21 & 20.4 \\
\hline & $61-70$ & 8 & 7.8 \\
\hline & $71<$ & 2 & 1.9 \\
\hline \multirow[t]{2}{*}{ Marital status } & Married & 99 & 96.1 \\
\hline & Single & 4 & 3.9 \\
\hline \multirow[t]{5}{*}{ Education } & $\begin{array}{l}\text { No formal educa- } \\
\text { tion }\end{array}$ & 6 & 5.8 \\
\hline & Primary & 17 & 16.5 \\
\hline & Secondary & 18 & 17.5 \\
\hline & Higher secondary & 6 & 5.8 \\
\hline & $\begin{array}{l}\text { Third level educa- } \\
\text { tion and above }\end{array}$ & 56 & 54.4 \\
\hline \multirow[t]{3}{*}{ Residence } & Village & 8 & 7.8 \\
\hline & Suburban & 23 & 22.3 \\
\hline & Urban & 70 & 68.0 \\
\hline \multirow[t]{6}{*}{ Occupation } & Employed & 68 & 66 \\
\hline & Self employed & 7 & 6.8 \\
\hline & Farmer & 4 & 3.9 \\
\hline & Unemployed & 4 & 3.9 \\
\hline & Housewife & 17 & 16.5 \\
\hline & Retired & 3 & 2.9 \\
\hline
\end{tabular}

$80 \%$ of the patients added salt to their daily meals and almost all of the males (81\%) were smokers. Differences and association of various socio-demographic information and risk factors are presented in Tables 2 and 3 respectively.

This data shows that the risk factors for stroke were consistently higher and significant amongst the younger, urban dwelling, well-educated and employed participants. Males had a statistically greater prevalence for high cholesterol and smoking than females. However it should be noted that, culturally, women do not smoke in Bangladesh.

\section{Previous knowledge on stroke}

About $73 \%$ of the patients reported that they knew they were at risk of stroke. $61 \%$ of the patients had been advised by a physician that their comorbidities put them at risk of stroke. However, only $7 \%$ of participants attended their doctors regularly for their health conditions, and 93\% patients did not see doctor until they felt unwell. This study suggests that the education level of participants positively correlated with a prior knowledge of stroke, as presented in Additional file 1. 
Table 2 Chi square analysis of response variables by selected socio-demographic factors

\begin{tabular}{|c|c|c|c|c|c|}
\hline Variables & $\begin{array}{l}\text { High blood pressure } \\
X^{2} \\
(\%)\end{array}$ & $\begin{array}{l}\text { High blood cholesterol } \\
x^{2} \\
(\%)\end{array}$ & $\begin{array}{l}\text { Diabetes } \\
x^{2} \\
(\%)\end{array}$ & $\begin{array}{l}\text { Added salt } \\
X^{2} \\
(\%)\end{array}$ & $\begin{array}{l}\text { Smoking } \\
x^{2} \\
(\%)\end{array}$ \\
\hline Gender & $x^{2}=3.16$ & $x^{2}=3.88^{*}$ & $x^{2}=1.74$ & $x^{2}=.59$ & $x^{2}=41.36^{*}$ \\
\hline Male & 88.8 & 73.8 & 73.8 & 81.3 & 81.3 \\
\hline Female & 73.9 & 52.2 & 87.0 & 73.9 & 0 \\
\hline Age & $x^{2}=11.17^{*}$ & $x^{2}=12.38^{*}$ & $x^{2}=4.41^{*}$ & $x^{2}=.63$ & $x^{2}=9.88^{*}$ \\
\hline Below 60 & 89.2 & 74.2 & 79.6 & 80.6 & 69.9 \\
\hline Above 60 & 50.0 & 20 & 50 & 70 & 20 \\
\hline Education & $x^{2}=11.91^{*}$ & $x^{2}=28.08^{*}$ & $x^{2}=10.87^{*}$ & $x^{2}=17.08^{*}$ & $x^{2}=47.27^{*}$ \\
\hline Below third level education & 72.3 & 42.6 & 61.7 & 61.7 & 29.8 \\
\hline Above third level education & 96.4 & 91.1 & 89.3 & 94.6 & 94.6 \\
\hline Occupation & $x^{2}=8.86^{*}$ & $x^{2}=10.86$ & $x^{2}=.60$ & $x^{2}=8.72^{*}$ & $x^{2}=58.23^{*}$ \\
\hline Employed & 91.1 & 77.2 & 78.5 & 86.1 & 84.8 \\
\hline Unemployed & 66.7 & 41.7 & 70.8 & 58.3 & .0 \\
\hline Residence & $x^{2}=8.80^{*}$ & $x^{2}=27.07^{*}$ & $x^{2}=22.94^{*}$ & $x^{2}=1.28$ & $x^{2}=9.94^{*}$ \\
\hline Rural and semi urban & 69.0 & 31.1 & 44.8 & 72.4 & 41.4 \\
\hline Urban & 91.19 & 83.8 & 89.2 & 82.4 & 47.3 \\
\hline
\end{tabular}

$* p<0.05$

Table 3 Binary logistic regression presenting the relationship of selected socio-demographic factors on various risk factors of stroke

\begin{tabular}{|c|c|c|c|c|c|}
\hline Variables & $\begin{array}{l}\text { Hypertension } \\
\text { AOR } \\
(95 \% \mathrm{Cl}) ; \mathrm{p}\end{array}$ & $\begin{array}{l}\text { High blood cholesterol } \\
\text { AOR } \\
(95 \% \mathrm{Cl}) ; \mathrm{p}\end{array}$ & $\begin{array}{l}\text { Diabetes } \\
\text { AOR } \\
(95 \% \mathrm{Cl}) ; \mathrm{p}\end{array}$ & $\begin{array}{l}\text { Added salt } \\
\text { AOR } \\
(95 \% \mathrm{Cl}) ; \mathrm{p}\end{array}$ & $\begin{array}{l}\text { Smoking } \\
\text { AOR } \\
(95 \% \mathrm{Cl}) ; \mathrm{p}\end{array}$ \\
\hline \multicolumn{6}{|l|}{ Gender } \\
\hline $\begin{array}{l}\text { Male } \\
\text { Female }\end{array}$ & $\begin{array}{l}2.78 \\
(.87-8.88) ; .08\end{array}$ & $\begin{array}{l}2.57 \\
(.98-6.71) ; .053\end{array}$ & $\begin{array}{l}.42 \\
(.11-1.56) ; .19\end{array}$ & $\begin{array}{l}1.52 \\
(.51-4.53) ; .444\end{array}$ & $\begin{array}{l}45.50 \\
(9.60-215.50) ; .000^{*}\end{array}$ \\
\hline \multicolumn{6}{|l|}{ Age } \\
\hline $\begin{array}{l}\text { Below } 60 \text { years } \\
\text { Above } 60 \text { years }\end{array}$ & $\begin{array}{l}8.30 \\
(2.04-33.74) ; .003^{*}\end{array}$ & $\begin{array}{l}11.50 \\
(2.28-57.97) ; .003^{*}\end{array}$ & $\begin{array}{l}3.89 \\
(1.02-14.84) ; .046^{*}\end{array}$ & $\begin{array}{l}1.78 \\
(.42-7.59) ; .43\end{array}$ & $\begin{array}{l}9.28 \\
(1.85-46.52) ; .007^{*}\end{array}$ \\
\hline \multicolumn{6}{|l|}{ Education } \\
\hline $\begin{array}{l}\text { Below third level education } \\
\text { Above third level education }\end{array}$ & $\begin{array}{l}.09 \\
(.021-.45) ; .003^{*}\end{array}$ & $\begin{array}{l}.07 \\
(.02-.21) ; .000^{*}\end{array}$ & $\begin{array}{l}.19 \\
(.06-.54) ; .002^{*}\end{array}$ & $\begin{array}{l}.09 \\
(.02-.33) ; .000^{*}\end{array}$ & $\begin{array}{l}.024 \\
(.00-.09) ; .000^{*}\end{array}$ \\
\hline \multicolumn{6}{|l|}{ Occupation } \\
\hline $\begin{array}{l}\text { Employed } \\
\text { Unemployed }\end{array}$ & $\begin{array}{l}5.14 \\
(1.62-16.24) ; .005^{*}\end{array}$ & $\begin{array}{l}4.74 \\
(1.80-12.47) ; .002^{*}\end{array}$ & $\begin{array}{l}1.50 \\
(.53-4.21) ; .439\end{array}$ & $\begin{array}{l}6.81 \\
(2.35-19.78) ; .000^{*}\end{array}$ & $\begin{array}{l}35.65 \\
(10.09-92.47) ; .000^{*}\end{array}$ \\
\hline \multicolumn{6}{|l|}{ Residence } \\
\hline $\begin{array}{l}\text { Rural and semi urban } \\
\text { Urban }\end{array}$ & 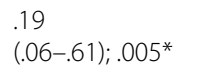 & $\begin{array}{l}.087 \\
(.032-.237) ; .000^{*}\end{array}$ & $\begin{array}{l}.09 \\
(.03-.27) ; .000^{*}\end{array}$ & $\begin{array}{l}.55 \\
(.20-1.53) ; .260\end{array}$ & $\begin{array}{l}.24 \\
(.09-.60) ; .002^{*}\end{array}$ \\
\hline
\end{tabular}

$O R$ adjusted odds ratio, $\mathrm{Cl}$ confidence interval

${ }^{*} p<0.05$

Initial management of stroke of those attending CRP

About $90 \%$ of the patients received immediate care in a general hospital or clinic upon onset of their stroke and the remaining $10 \%$ were treated at home by untrained traditional medical practitioners. On presentation for those attending hospital or clinic, 96\% underwent diagnostic imaging, either via Magnetic Resonance Imaging
(MRI) or Computerized Tomography (CT). About 92\% of patients discussed their results with a neurologist. After their incident, about $84 \%$ of patients were initially managed by registered physicians, with $10 \%$ seen by unqualified traditional village doctors. About $50 \%$ of patients received their stroke treatment at tertiary level hospitals. Of the study group, only $22 \%$ had been advised to seek 
further rehabilitation at CRP by their physician. $61 \%$ of the group was recommended to attend CRP by previous patients and $11 \%$ by acquaintances.

\section{Information regarding care-givers}

All the patients had personal care-givers. $68 \%$ of male patients were cared for by their spouses, the majority being housewives. For female patients, daughters accounted for $80 \%$ of care-givers in this demographic.

\section{Financial cost of stroke rehabilitation}

Stroke is an extra financial cost for a family; the participants in this study reported that their average monthly expenditure was US $\$ 328$ for rehabilitation services alone. Only $10 \%$ of patients received any sort of financial aid, usually from their employers, with the remainder paying independently.

\section{Discussion}

In this study, we provided a snapshot demographic view of patients attending CRP for stroke rehabilitation. In addition to recording age, gender and area, we also attempted to identify those who had comorbidities that could contribute to the risk of stroke, and ascertain whether the patients had any knowledge of stroke prior to its occurrence.

The socio-demographic information revealed that the group most at risk to stroke are males under the age of 60 years, living in urban areas and educated to a third level.

Though most commonly associated with the elderly [9], the global incidence of stroke affecting those below the age of 45 years is significantly higher in low income, developing countries. In these countries, up to $30 \%$ of all strokes occur in people under 45 , compared to only $5 \%$ in western countries [10]. The average age of the participants in our study was 49 years, with $69.9 \%$ below the age of 50 . This figure is low in comparison to the mean age of stroke patients in many other countries, including neighbouring India $[9,11]$.

Many participants in this study had stroke risk factors prior to onset. Mohammad et al. data on stroke patients from different hospitals in Bangladesh showed $57.6 \%$ of patients had a history of hypertension, $23 \%$ had diabetes, $44.6 \%$ had a history of smoking [12]. Our results for these risk factors were greater, however, at $85 \%, 77 \%$ and $81 \%$ respectively. Further investigation is required to determine the causes behind this trend. We found that there was a significantly higher prevalence of hypertension and diabetes among higher-educated employed people aged between 41 and 60 . Among the participants as a whole, about $70 \%$ knew that they were at risk from stroke, and $61 \%$ of the group had had these risks highlighted to them by a physician. However, only $7 \%$ of the patients visited a doctor prior to their stroke. Amongst those who had received higher education, the majority considered themselves well informed about stroke, and most (92\%) had had their risk factors highlighted to them by a physician. Thus, it can be inferred that the lifestyle and health behaviour of educated people are not conducive to healthy lifestyle choices. It appears that participants who had been informed of the risk of stroke failed to take any preventative measures, and this has been found to be common amongst patients with chronic disorders [13].

Despite the fact that only $34.27 \%$ [14] of the population of Bangladesh live in urban areas, $68 \%$ of the participants of this study lived in urbanised areas. These findings support the study by Hossain et al. which found that most patients treated for stroke in Bangladeshi tertiary level hospitals came from urban areas [15]. Fatema et al. suggests that the prevalence of cardiovascular disease in urban areas is a potential reason for an increase in this demographic [16]. It can be assumed that educated individuals, living in urban areas and with an occupation which is less physically active, adopt additional poor lifestyle choices such as smoking. We conducted this study at CRP, which is near Dhaka, the capital of Bangladesh, which may account for the prevalence of urban-dwelling, educated, employed participants. We would need a further countrywide study to determine the correlation between stroke and urban dwelling.

This study found that the majority of participants received their initial care at a hospital or a clinic and were treated by a registered physician. Despite the scarcity of trained neurologists and neuro-imaging facilities in Bangladesh, $92 \%$ of patients in this study reported that they had received treatment by neurologists and nearly all patients had undergone either an MRI or CT scan for their condition.

This study also found that most patients who attended CRP had been recommended to do so by patients who were beneficiaries of CRP's services previously. Only $22 \%$ of patients had been advised to seek rehabilitation by their physician. In our study, all patients received full care from their family members, either from a spouse or daughter. Dewey et al. found that approximately $74 \%$ of stroke survivors cannot manage their daily activities without assistance and, typically, family members were required to provide this care [17]. According to this study, wives and daughters were the main carers for men and women respectively and found that no patients had utilised the services of paid professional caregivers. In terms of occupations, the wives were predominantly housewives. Lutz et al. states that caring for stroke patients is a difficult task and has a huge impact on a caregiver's own health and wellbeing [18]. 
There is also a financial cost associated with providing care for a family member with a stroke. Heeley et al. states that stroke creates considerable economic hardship, particularly when the individuals had been the main financial earners of the family [19].By the time they arrived at CRP, patients had already paid considerably for their stroke management. In addition to their typical monthly expenditure families, had to pay an average US $\$ 328$ per month to support their rehabilitation while at CRP. At the time of the study, the average annual income in Bangladesh was US \$1466 [20]. Thus, the average monthly expenditure for a participant's rehabilitation equates to more than one-fifth of their annual income. About $90 \%$ patients were dependent on their families to bear this expense and did not receive any organisational or governmental help. Previous studies have found that these additional costs exacerbate the poverty of people in many developing countries, such as Bangladesh [21]. Though the financial impact of health care cost depends on the financial capacity of people, it is estimated that annually about $4.2 \%$ of people are forced into extreme poverty to meet healthcare expenditure in Bangladesh [22].

\section{Limitations}

This study consisted of a small cohort of participants, and focused on a single rehabilitation facility. We assumed that the participants' accounts of their healthcare journey and healthcare conditions were accurate. We provided a very broad overview of a range of demographics and their links to the participants' health conditions. An indepth study could be of great benefit.

\section{Additional file}

Additional file 1: Table S1. Level of education and awareness of the presence of stroke risk factors.

\begin{abstract}
Abbreviations
DALYs: disability-adjusted life years; CRP: Centre for the Rehabilitation of the Paralysed; TIA: transient ischemic attack; IRB: Institutional Review Board; BHPI: Bangladesh Health Professions Institute; SPSS: Statistical Package for the Social Sciences; MRI: magnetic resonance imaging; CT scan: computed tomography scan; OR: odds ratio; $\mathrm{Cl}$ : confidence interval.
\end{abstract}

\section{Authors' contributions}

FAM designed the study, trained data collectors, analysed data, interpreted data and drafted manuscript. MSI, FSR and FF analyzed and interpreted data. All authors read and approved the final manuscript.

\section{Author details}

${ }^{1}$ Department of Physiotherapy, Bangladesh Health Professions Institute (BHPI), CRP. Savar, Dhaka 1343, Bangladesh. ${ }^{2}$ Department of Physiotherapy, Centre for the Rehabilitation of the Paralysed (CRP), CRP, Savar, Dhaka 1343, Bangladesh.

\section{Acknowledgements}

We are grateful to the participants of this study and those who helped us with the collection of data.

\section{Competing interests}

The authors declare that they have no competing interests.

\section{Availability of data and materials}

The dataset used in this study is available by contacting Firoz Ahmed Mamin (mamincns@gmail.com).

\section{Consent for publication}

Not applicable.

\section{Ethics approval and consent to participate}

A written consent form was taken from each selected participant before data collection. Ethical permission was obtained from the Institutional Review Board (IRB) of the Bangladesh Health Professions Institute (BHPI), the academic institute of CRP, before conducting this study.

\section{Funding}

This research did not receive any funding from anywhere.

\section{Publisher's Note}

Springer Nature remains neutral with regard to jurisdictional claims in published maps and institutional affiliations.

Received: 8 March 2017 Accepted: 23 October 2017

Published online: 27 October 2017

\section{References}

1. Mensah GA, Norrving B, Feigin VL. The global burden of stroke. Neuroepidemiology. 2015. https://doi.org/10.1159/000441082.

2. Wang $\mathrm{H}$, Naghavi $\mathrm{M}$, Allen $\mathrm{C}$, et al. Global, regional, and national life expectancy, all-cause mortality, and cause-specific mortality for 249 causes of death, 1980-2015: a systematic analysis for the Global Burden of Disease Study 2015. Lancet. 2016. https://doi.org/10.1016/ S0140-6736(16)31012-1.

3. Feigin VL, Norrving B, George M, Foltz JL, Roth G, Mensah G. Prevention of stroke: a strategic global imperative. Nat Rev Neurol. 2016. https://doi. org/10.1038/nrneurol.2016.107.

4. El-Saharty, Karar Z, Tracey L, et al. Tackling noncommunicable diseases in Bangladesh: now is the time. Directions in development. Washington DC: World Bank; 2013. https://doi.org/10.1596/978-0-8213-9920-0.

5. Mamun M, Rumana N, Pervin K, et al. Emerging burden of cardiovascular diseases in Bangladesh. J Atheroscler Thromb. 2015. https://doi. org/10.5551/jat.30445.

6. Islam MN, Moniruzzaman M, Khalil MI, et al. Burden of stroke in Bangladesh. Int J Stroke. 2013. https://doi.org/10.1111/j.1747-4949.2012.00885.x.

7. Young J, Forster A. Review of stroke rehabilitation. BMJ. 2007. https://doi. org/10.1136/bmj.39059.456794.68.

8. Ahmed M, Alam B, Anwar I, et al. Bangladesh health system review. Health Syst Trans. 2015;5(3):214.

9. Krishnamurthi RV, Feigin VL, Forouzanfar MH, et al. Global and regional burden of first-ever ischaemic and haemorrhagic stroke during 19902010: findings from the Global Burden of Disease Study 2010. Lancet Glob Health. 2013. https://doi.org/10.1016/S2214-109X(13)70089-5.

10. Marini C, Russo T, Felzani G. Incidence of stroke in young adults: a review. Stroke Res Treat. 2010. https://doi.org/10.4061/2011/535672.

11. Pandian JD, Sudhan P. Stroke epidemiology and stroke care services in India. J stroke. 2013. https://doi.org/10.5853/jos.2013.15.3.128.

12. Mohammad QD, Habib M, Mondal BA, et al. Stroke in Bangladeshi patients and risk factor. Mymenshing Med J. 2014;23(3):520-9.

13. Joshi Shashank R, Shah Siddharth N. Control of blood pressure in India: rule of halves still very much valid. J Assoc Physicians India. 2003;51:151-2. 
14. The World Bank. Data on Urban population. 2015. http://data.worldbank. org/indicator/SP.URB.TOTL.IN.ZS? locations=BD. Accessed 4 Mar 2017

15. Hossain AM, Ahmed NU, Rahman M, Sadhya G, Fatema K. Analysis of sociodemographic and clinical factors associated with hospitalized stroke patients of Bangladesh. Faridpur Med Coll. J. 2011;6(1):19-23.

16. Fatema K, Zwar NA, Zeba Z, Milton AH, Rahman B, Ali L. Clinical and biochemical characterization of high risk and not high risk for cardiovascular disease adults in a population from peripheral region of Bangladesh. BMC Public Health. 2015. https://doi.org/10.1186/s12889-015-1919-7.

17. Dewey HM, Thrift AG, Mihalopoulos C, et al. Informal care for stroke survivors. results from the north east Melbourne Stroke Incidence Study (NEMESIS). Stroke. 2002. https://doi.org/10.1161/01.STR.0000013067.24300.B0.

18. Lutz B, Young M, Cox K, Martz C, et al. The crisis of stroke: experiences of patients and their family caregivers. Top Stroke Rehabil. 2011. https://doi. org/10.1310/tsr1806-786.
19. Heeley $E$, Anderson CS, Huang Y, et al. Role of health insurance in averting economic hardship in families after acute stroke in China. Stroke. 2009. https://doi.org/10.1161/STROKEAHA.108.540054.

20. Bangladesh Open Data. Bangladesh by Numbers; 2017. http://data.gov. bd. Accessed 16 Aug 2017.

21. Doorslaer E, Donnell O, Ravindra P, et al. Catastrophic payments for health care in Asia. Health Econ. 2007;16:1159-84.

22. Huq NM, Al-Amin AQ, Howlader SR, Kabir MA. Paying out of pocket for healthcare in Bangladesh - a burden on poor? Iran J Public Health. 2015;44(7):1024-5.

\section{Submit your next manuscript to BioMed Central and we will help you at every step:}

- We accept pre-submission inquiries

- Our selector tool helps you to find the most relevant journal

- We provide round the clock customer support

- Convenient online submission

- Thorough peer review

- Inclusion in PubMed and all major indexing services

- Maximum visibility for your research

Submit your manuscript at www.biomedcentral com/submit 